\title{
Folate deficiency and aberrant DNA methylation and expression of FHIT gene were associated with cervical pathogenesis
}

\author{
QIAOLING LI ${ }^{1}$, LING DING $^{1}$, NAN JING ${ }^{1}$, CHUNLIANG LIU $^{1}$, ZUOKAI YANG $^{1}$, \\ FANG CHEN $^{1}$, LIFANG HOU ${ }^{1,2}$ and JINTAO WANG ${ }^{1}$ \\ ${ }^{1}$ Department of Epidemiology, School of Public Health, Shanxi Medical University, Taiyuan, \\ Shanxi 030001, P.R. China; ${ }^{2}$ Department of Preventive Medicine, Robert H. Lurie Comprehensive Cancer Center, \\ Feinberg School of Medicine, Northwestern University, Chicago, IL 60611, USA
}

Received April 9, 2017; Accepted October 20, 2017

DOI: 10.3892/ol.2017.7471

\begin{abstract}
Aberrant DNA methylation is a recognized feature in various types of human cancer, and folate has a vital role in the epigenetics of mammalian cells by supplying methyl groups for DNA methylation reactions. Fragile histidine triad (FHIT) is a tumor suppressor gene that is frequently silenced in cervical cancer (CC) and preneoplastic lesions. Promoter hypermethylation was previously observed in CC, and its epigenetic silencing has been observed at mRNA or protein levels. Changes in folate intake to modulate DNA methylation may be a mechanistic link to cancer, but this remains to be elucidated. The aim of the present study was to evaluate the influences of folate on FHIT gene methylation and expression in the progression of cervical cancerization. In the present study, red blood cell (RBC) folate levels, FHIT gene methylation status, and mRNA and protein expression levels were detected in 254 women, including normal cervix (NC, $n=80$ ), cervical intraepithelial neoplasm grade 1 (CIN1, $\mathrm{n}=55$; CIN2/3, $\mathrm{n}=55$ ) and cervical squamous cell carcinoma (SCC, $n=64$ ) samples. The methylation status of FHIT gene and its mRNA and protein expression levels were measured in CaSki (HPV16 positive) and C33A (HPV16 negative) CC cells treated with different concentrations of folate. The results indicated that FHIT gene methylation rate increased with the severity of cervix lesions, however, RBC folate levels, FHIT mRNA and protein expression levels were reduced. The
\end{abstract}

Correspondence to: Professor Jintao Wang, Department of Epidemiology, School of Public Health, Shanxi Medical University, 56 Xin Jian Nan Road, Taiyuan, Shanxi 030001, P.R. China E-mail: wangjt59@163.com

Professor Lifang Hou, Department of Preventive Medicine, Robert H. Lurie Comprehensive Cancer Center, Feinberg School of Medicine, Northwestern University, 303 E. Chicago Avenue, Olson Pavilion 8350, Chicago, IL 60611, USA

E-mail: 1-hou@northwestern.edu

Key words: folate, FHIT gene, methylation, expression, cervical cancerization, cervical cancer cells proliferation inhibition rate, apoptosis rate, and FHIT protein and mRNA expression levels increased along with rising concentrations of folate, whereas the degree of FHIT gene methylation gradually weakened in CaSki or C33A cell lines. The present findings indicated that folate deficiency, FHIT gene promoter hypermethylation and reduced expression were significantly associated with cervical carcinogenesis. The results indicated that folate was able to enhance apoptosis and inhibit the cervical cell proliferation while regulating FHIT gene methylation and expression. Adequate intake of folate to maintain normal DNA methylation status is an effective way for cervical lesions prevention, and demethylation treatment may offer a new strategy for therapy of CC.

\section{Introduction}

Cervical cancer (CC) is the leading gynecological malignancy worldwide, the global incidence increased from 378,000 cases per year in 1980 to 454,000 cases per year in 2010, with a $0.6 \%$ annual rate of increase (1). High-risk-human papillomavirus (HR-HPV) persistent infection is a main factor on cervical intraepithelial neoplasia (CIN) and CC $(2,3)$, but not all women infected with HPV develop CC. It is indicated that other factors may involved along with HPV in inducing cervical carcinogenesis. HPV DNA often attack host cell DNA in the process of carcinogenesis and occur mostly in the gene fragile site. Interesting, low folate status could increase the probability of occurring gene fragile site further promoting the integration between HPV DNA and host cell DNA (4). Folate is a water-soluble B-vitamin and an important cofactor in one-carbon metabolism in which folate participates in DNA synthesis and regulating methylation reactions, adequate folate status is an important determinant of normal DNA methylation status $(5,6)$. Deficient folate levels have been shown in murine prostate cancer models to result in $\mathrm{CpG}$ island hypermethylation and misincorporation of uracil into DNA strands, leading to genetic and epigenetic instability that is characteristic of carcinogenesis (7). Epidemiological studies have demonstrated an inverse relationship between folate status and the risks of some malignancies including cancer of colon, esophagus, stomach, pancreas, lung, cervix, ovary, breast and leukemia $(8,9)$, and 
folate deficiency contributes to CC risk at several sites (10), but there were less reports about the effects of folate on the progression from the normal cervix (NC), CIN to cancer. Additional, Red cell folate is not affected by folic acid intake and is more representative of the actual folic acid levels in the body, and though our previous researches have suggested that serum folate levels were inversely associated with CC risk (11), it is still remains unclear that the modification of red blood cell (RBC) folate in the progression of cervical carcinogenesis.

Converging evidence from epidemiological and molecular studies have suggested that the alteration of DNA methylation is one of most consistent epigenetic changes in human cancers (12-14), aberrant promoter hypermethylation is an important mechanism for function loss of certain tumor suppressor genes in tumors (15-17). Fragile histidine triad (FHIT) gene is a tumor suppressor gene which could regulate cell apoptosis and proliferation (18) and is rich in benign squamous epithelial cells. Some study showed that FHIT gene expression decreased or was absent in tumorigenesis, especially epithelial tumour (19). Aberrant FHIT gene expression caused by promoter region hypermethylation has been found in some cancers, our previous researches also have suggested that FHIT gene hypermethylation and protein low expression could increase the risk of CC and precancerous lesions (20). LOH-dependent FHIT decreased expression have been linked with high proliferation and low apoptotic index in tumor cells, it has also been proven that co-hypermethylation of FHIT gene and p16 (a tumor suppressor gene) gene in early stage of cancer is poor prognostic factor and can confer cisplatin resistance in cancer cells (21). However, the effects of folate on FHIT gene methylation and expression in $\mathrm{CC}$ is unclear.

Folate deficiency and FHIT gene hypermethylation were the risk factors of cervical lesions, considering folate and FHIT inactivation closely related to DNA methylation, we undertook a study intended to evaluate the associations between RBC folate levels and FHIT gene methylation status, mRNA and protein expression levels in population with multistage cervical lesions. Meanwhile, we observed the role of folate on cell proliferation and apoptosis of CC cells CaSki (HPV16 positive) and C33A (HPV negative) and evaluated whether the effects were developed through mediating DNA methylation status and expression of FHIT gene. A deeper understanding of the role of folate and FHIT gene in human cervical tissues and cancer cells can provide insight into early mechanisms of cervical carcinogenesis.

\section{Materials and methods}

Patients and samples. The participants were diagnosed by pathology, including 80 women with NC, 110 patients with CIN1 $(n=55)$ and CIN2/3 $(n=55)$ and 64 patients with cervical squamous cell carcinoma (SCC). All the study participants were collected from Shanxi Tumor Hospital and Second Hospital of Shanxi Medical University (Taiyuan, China), and lived in the Shanxi province for more than five years. Participants were excluded with nutritional megaloblastic anemia, hemolytic disease, leukemia, liver disease, other malignant tumors and taking B vitamins within three months. The information of demographic characteristics, lifestyle, personal hygiene behavior and reproductive factors known to be associated with cervical lesions was collected using structured questionnaire. Prior to surgery or other treatments, $5 \mathrm{ml}$ anticoagulant blood and non anticoagulant blood were obtained from all participants after an overnight fasting and stored at $-80^{\circ} \mathrm{C}$ until analysis. Cervical tissues were obtained from all participants who underwent surgery or biopsy under colposcope, and was stored in $-80^{\circ} \mathrm{C}$ refrigerator immediately. Informed consent will be signed by eligible participants who agree to participate in the study. The study was approved by Shanxi Medical University Science Research Ethics Committee.

Cells culture and folate interventions. CC cell lines C33A (HPV negative) and CaSki (HPV16 positive) were cultured in MEM-EBSS and RPMI-1640 culture medium (Chinese Academy of Medical Sciences) at $37^{\circ} \mathrm{C}$ in a $5 \% \mathrm{CO}_{2}$ atmosphere, respectively. MEM-EBSS and RPMI-1640 culture medium: $10 \%$ fetal bovine serum and 100 units $/ \mathrm{ml}$ of penicillin and streptomycin were dissolved in ready-to-use MEM-EBSS/RPMI-1640 culture solution. CaSki and C33A cells in the logarithmic phase of growth were cultured for $24 \mathrm{~h}$ and then transfered to folate culture medium at concentrations of $1.0 \mu \mathrm{g} / \mathrm{ml}$ (as control group), 10, 100, 250, 500 and $1,000 \mu \mathrm{g} / \mathrm{ml}$ for $48 \mathrm{~h}$. Folate culture medium: first, prepare $2 \mathrm{mg} / \mathrm{ml}$ folate reserve solution (dissolve $2 \mathrm{~g}$ folate into $100 \mathrm{ml}$ MEM-EBSS/RPMI-1640 culture solution, and adjust $\mathrm{PH}$ to 7.2 with $7.4 \% \mathrm{NaOH}$ ), and then add appropriate amount of folate reserve solution and $10 \%$ fetal bovine serum and 100 units $/ \mathrm{ml}$ of penicillin and streptomycin to ready-to-use MEM-EBSS/RPMI-1640 culture solution, so that final concentration were $1.0,10,100,250,500$ and $1,000 \mu \mathrm{g} / \mathrm{ml}$.

Testing HPV16 infection by PCR. Cervical tissue DNA was extracted by proteinase $\mathrm{K}$ digestion and a modified phenol-chloroform protocol. HPV16 DNA was determined by PCR as described before (22). The HPV16E2 primers were as follows: P1, AAGGGCGTAACCGAAATCGGT; P2, CAT ATACCTCACGTCGCAG, and the HPV16 E6 primers were as follows: P1, CTTGGGCACCGAAGAAACAC; P2, TTG GTCACGTTGCCATTCAC. Either E2 or E6 positive can be determined as HPV16 positive.

Detecting RBC folate levels by microbiological method. Serum and whole blood samples were treated with $1 \%$ ascorbic acid and folate concentration were determined by microbiological method as described before (11). Each sample was analyzed in duplicate. Serum folate concentrations were obtained automatically by standard curve. RBC folate concentration $=[$ whole blood folate concentration-serum folate concentration x (1-hematocrit)]/hematocrit.

Detecting cells proliferation ability by cell counting and apoptosis by flow cytometry. The C33A and CaSki cells were cultured with different folate concentrations $(1.0,10,250$, 500 and $1,000 \mu \mathrm{g} / \mathrm{ml}$ ) for $48 \mathrm{~h}$. The cell proliferation ability were measured by cell counting using microscopy $(4 \times 10)$ after trypan blue staining, and apoptosis were tested by flow cytometry with Annexin V-FITC/PI apoptosis detection kit (KGA108; Nanjing KeyGen Biotech Co., Ltd., Nanjing, 
China). Proliferation inhibition rate $=($ control group cell counts-interventional group cell counts)/control group cell counts.

Detecting FHIT gene methylation status by MSP. Cervical tissues and cells DNA was extracted by phenol-chloroform extraction. $20 \mu \mathrm{l}$ DNA solution was used for detecting FHIT gene methylation status by methylation-specific polymerase chain reaction (MSP) as described before (23). MSP primers for FHIT (Gene ID:2272) were as follows; FHIT (M) P1, 5'-TTG GGGCGCGGGTTTGGGTTTTTACGC-3'; P2, 5'-CGTAAA CGACGCCGACCCCACTA-3'; FHIT (U) P1, 5'-TTGGGG TGTGGGTTTGGGTTTTTATG-3'; P2, 5'-CATAAACAA CACCAACCCCACTA-3'. The PCR product was separated on a $2 \%$ agarose gel electrophoresis at $74 \mathrm{bp}$. FHIT gene methylated and unmethylated bands were obtained with Vilber Lourmat (VILBER CV-A50C; Marne La Valée, France).

Measuring FHIT mRNA expression levels in cervical tissues and cells by $q P C R$. Total RNA extracted from tissue and cells samples was isolated with Trizol reagent (Takara Bio, Inc., Otsu, Japan) following the manufacturer's instruction. qPCR was carried out using an Mx3005p ${ }^{\mathrm{TM}}$ Real-Time PCR Detection System (Stratagene; Agilent Technologies, Inc., Santa Clara, CA, USA) and the Prime Script ${ }^{\mathrm{TM}}$ RT-PCR kit (Takara Bio, Inc.) according to the manufacturer's instructions to confirm the expression levels of mRNA. In brief, the reverse transcription reaction with a BioRad PTC-200 PCR Detection System (Bio-Rad Laboratories, Inc., Hercules, CA, USA) was carried out in a $10 \mu \mathrm{l}$ volume with $1 \mu \mathrm{g}$ of total RNA, at $37^{\circ} \mathrm{C}$ for $15 \mathrm{~min}, 85^{\circ} \mathrm{C}$ for $5 \mathrm{sec}$, and then the cDNA were stored at $4^{\circ} \mathrm{C}$ until use. A total of $2 \mu \mathrm{l}$ of the RT product was used in each PCR. The PCR cycling began with template denature at $95^{\circ} \mathrm{C}$ for $30 \mathrm{sec}$, followed by 40 cycles of $95^{\circ} \mathrm{C}$ for $5 \mathrm{sec}$, annealing at $60^{\circ} \mathrm{C}$ for $30 \mathrm{sec}$ and extension at $95^{\circ} \mathrm{C}$ for $15 \mathrm{sec}$, and followed by $60^{\circ} \mathrm{C}$ for $30 \mathrm{sec}$ and $95^{\circ} \mathrm{C}$ for $15 \mathrm{sec}$. The FHIT primers were as follows: upstream 5'-GCAGCT CTGCGGGTCTACTTTC-3'; and downstream 5'-TCTTCA AACTGGTTGGCAATAGCT C-3'. The $\beta$-actin (GAPDH) primers were as follows: upstream 5'-TGGCACCCAGCA CAATGAA-3'; and downstream 5'-CTAAGTCATAGTCCG CCTAGAAGCA-3'. Relative quantification of FHIT mRNA was performed using $2^{-\Delta \Delta C q}$, The higher $2^{-\Delta \Delta C q}$ was, the higher the levels of mRNA were.

Measuring the expression levels of FHIT protein in cervical tissues and cells by western blotting. Cervical tissues and cells were lysed in WIP (Tissue and Cell lysis solution; Bioss Inc., Beijing, China) and PMSF (Amresco). Protein was quantitated with BCA protein assay (Wuhan Boster Biological Technology, Ltd., Wuhan, China). The FHIT protein expression levels were detected as described before (24) using rabbit monoclonal anti-FHIT (1:800; Abcam, Cambridge, UK). Densitometric analysis was performed by Quantity One software (Bio-Rad Laboratories, Inc.). Relative expression quantity of FHIT protein was represented by OD ratio of the target band to $\beta$-actin band.

Statistical analysis. All the in vitro experiments were independently repeated three times. Data analyses were performed with SPSS (version 16.0; SPSS, Inc., Chicago, IL, USA) statistical software. Differences between groups were assessed by ANOVA, Kruskal-Wallis H test, Bonferroni test, Chi-square test and trend of Chi-square test. Correlation was analyzed by spearman rank correlation. Multinomial logistic regression model was used to estimate odds ratio (OR) and adjusted OR (aOR) after adjusting potential covariates and OR 95\% confidence intervals $(95 \% \mathrm{CI})$. Statistical significance was set at $\alpha=0.05$.

\section{Results}

Demographic characteristics and relevant factors of cervical lesions. Demographic characteristics and relevant factors analysis showed that low education degree, seldom vaginal cleaning, higher number of pregnancy and parity, gynecological history, peasant occupation and induced abortion history were risk factors for cervical lesions (Table I). While, there were no significant differences on the distribution of age, birth place, race and marital status in each group $(\mathrm{P}>0.05)$.

$R B C$ folate levels. The levels of RBC folate were significantly different in NC, CIN and SCC groups $(\mathrm{H}=43.68, \mathrm{P}<0.001)$, and showed decreasing trend $\left(\chi_{\text {trend }}^{2}=21.91, \mathrm{P}<0.001\right)$. After multiple comparisons by adopting the Bonferroni test, we found levels of RBC folate in CIN2/3 and SCC groups were significantly lower than in CIN1 or NC groups, in CIN2/3 group was significantly lower than in CIN1 group. Further, we defined the $50 \%$ point value of RBC folate levels in NC group (275.42) as cut-off point to carry on qualitative analysis, the results showed that the OR and aOR in SCC group was higher than in CIN groups (Table II).

FHIT gene methylation status and expression levels. FHIT gene methylation rate in CIN1 (16.4\%), CIN2/3 (25.5\%) and SCC $(40.6 \%)$ groups was significantly higher than in NC $(5.0 \%)$ group. Along with the severity of cervical lesions, FHIT gene methylation rate and OR and aOR gradually increased $\left(\chi_{\text {trend }}^{2}=28.34, \mathrm{P}<0.001\right)$ (Table III).

The average expression levels of FHIT mRNA were significantly different in NC, CIN1, CIN2/3 and SCC groups $(H=60.17, \mathrm{P}<0.001)$, and showed an decreasing trend with the severity of cervical lesions (Fig. 1). The expression levels of FHIT mRNA in groups of SCC $(\mathrm{P}<0.001)$ and CIN2/3 $(\mathrm{P}=0.003)$ were significantly lower than NC group after using Bonferroni test. The positive rate of low FHIT mRNA was increased gradually with the severity of the cervix lesions $\left(\chi_{\text {trend }}^{2}=40.58, \mathrm{P}<0.001\right)$ with $50 \%$ point value of mRNA expression levels of FHIT in NC group as a cut-off point.

The average expression levels of FHIT protein were significantly different in cervical lesions groups $(H=52.23, \mathrm{P}<0.001)$, and showed an decreasing trend with growing severity of cervical lesions (Fig. 1). The expression levels of FHIT protein were significantly lower in groups of SCC $(\mathrm{P}<0.001), \mathrm{CIN} 2 / 3$ $(\mathrm{P}<0.001)$ and CIN1 $(\mathrm{P}=0.001)$ than $\mathrm{NC}$ group after using Bonferroni test. Furthermore, $50 \%$ point value of expression levels of FHIT protein in NC group (1.26) was defined as cut-off point, our results showed that positive rate of FHIT protein low expression increased gradually with the severity of cervix lesions $\left(\chi_{\text {trend }}^{2}=56.22, \mathrm{P}<0.001\right)$. 
Table I. Related factors analysis of cervical lesions.

\begin{tabular}{|c|c|c|c|c|c|c|}
\hline Variables & $\mathrm{NC}$ & CIN1 & CIN2/3 & $\mathrm{SCC}$ & $\chi^{2}$ & P-value \\
\hline HPV16 infection & & & & & 36.86 & $<0.001$ \\
\hline Yes & $14(17.5)$ & $23(41.8)$ & $31(56.3)$ & $41(64.1)$ & & \\
\hline No & $66(82.5)$ & $32(58.2)$ & $24(43.6)$ & $23(35.9)$ & & \\
\hline Occupation & & & & & 17.12 & 0.001 \\
\hline Peasant & $48(60.0)$ & $27(49.1)$ & $30(54.5)$ & $53(82.8)$ & & \\
\hline Other & $32(40.0)$ & $28(50.9)$ & $25(45.5)$ & $11(17.2)$ & & \\
\hline Education degree & & & & & 24.14 & $<0.001$ \\
\hline Under middle school & $17(21.3)$ & $19(34.5)$ & $21(38.2)$ & $39(60.9)$ & & \\
\hline Middle school above & $63(78.7)$ & $36(65.5)$ & $34(61.8)$ & $25(39.1)$ & & \\
\hline Frequency of vaginal cleaning & & & & & 31.79 & $<0.001$ \\
\hline$\geq 3$ times/week & $46(57.5)$ & $18(32.7)$ & $26(47.3)$ & $16(25.0)$ & & \\
\hline 3 times/week-1 time/month & $32(40.0)$ & $31(56.4)$ & $16(29.1)$ & $33(51.6)$ & & \\
\hline$\leq 1$ time/month & $2(2.5)$ & $6(10.9)$ & $13(23.6)$ & $15(23.4)$ & & \\
\hline Gynecological history & & & & & 21.19 & $<0.001$ \\
\hline Yes & $6(7.5)$ & $16(29.1)$ & $19(34.5)$ & $24(37.5)$ & & \\
\hline No & $74(92.5)$ & $39(70.9)$ & $36(65.5)$ & $40(62.5)$ & & \\
\hline Induced abortion history & & & & & 15.81 & 0.001 \\
\hline Yes & $29(36.3)$ & $32(58.2)$ & $33(60.0)$ & $43(67.2)$ & & \\
\hline No & $51(63.7)$ & $23(41.8)$ & $22(40.0)$ & $21(32.8)$ & & \\
\hline Number of parity & & & & & 12.57 & 0.05 \\
\hline$\leq 2$ & $35(43.8)$ & $17(30.9)$ & $27(49.1)$ & $16(25.0)$ & & \\
\hline $3-4$ & $20(25.0)$ & $18(32.7)$ & $16(29.1)$ & $18(28.1)$ & & \\
\hline$>4$ & $25(31.2)$ & $20(36.4)$ & $12(21.8)$ & $30(46.9)$ & & \\
\hline Number of pregnancy & & & & & 15.94 & 0.01 \\
\hline$\leq 2$ & $38(47.5)$ & $27(49.1)$ & $18(32.7)$ & $20(31.3)$ & & \\
\hline $3-4$ & $30(37.5)$ & $17(30.9)$ & $15(27.3)$ & $21(32.8)$ & & \\
\hline$>4$ & $12(15.0)$ & $11(20.0)$ & $22(40.0)$ & $23(35.9)$ & & \\
\hline
\end{tabular}

Data in brackets are constituent ratio (\%). NC, normal cervix; CIN, cervical intraepithelial neoplasm; SCC, squamous cell carcinoma.

Table II. RBC folate levels (ng/ml) in different groups.

\begin{tabular}{lccccc}
\hline Group & $\mathrm{n}$ & $\begin{array}{c}\text { RBC folate } \\
(\mathrm{M} \pm \mathrm{Q})^{\mathrm{a}}\end{array}$ & $\begin{array}{c}\text { Low levels } \\
(\leq 275.42)\end{array}$ & OR $(95 \% \mathrm{CI})$ & $\mathrm{aOR}^{\mathrm{b}}(95 \% \mathrm{CI})$ \\
\hline $\mathrm{NC}$ & 80 & $275.42 \pm 54.64^{\mathrm{c}}$ & $40(50.0)$ & 1.00 & 1.00 \\
$\mathrm{CIN} 1$ & 55 & $259.36 \pm 43.67^{\mathrm{c}}$ & $34(61.8)$ & $1.62(0.81-3.26)$ & $2.00(0.92-4.35)$ \\
$\mathrm{CIN} 2 / 3$ & 55 & $249.23 \pm 34.59^{\mathrm{d}}$ & $47(85.5)$ & $5.88(2.47-14.00)$ & $7.96(2.97-21.35)$ \\
SCC & 64 & $226.04 \pm 54.69^{\mathrm{d}}$ & $52(81.3)$ & $4.33(2.02-9.32)$ & $8.53(3.12-23.29)$ \\
& & $H=43.68, \mathrm{P}<0.001$ & $\chi_{\text {trend }}^{2}=21.91, \mathrm{P}<0.001$ \\
\hline
\end{tabular}

${ }^{a}$ Median \pm quartile range. ${ }^{\mathrm{b}} \mathrm{aOR}$, adjusted $\mathrm{OR}$, multivariable adjustment for education degree, occupation, frequency of vaginal cleaning, number of pregnancy and parity, induced abortion history, gynecological history and HPV16 infection. ${ }^{\mathrm{c}, \mathrm{d}}$ Different letters indicate significant differences. NC, normal cervix; CIN, cervical intraepithelial neoplasm; SCC, squamous cell carcinoma; OR, odds ratio; CI, confidence interval; RBC, red blood cell.

FHIT gene methylation status and expression levels analysis by folate status and cervical lesions status. Spearman rank correlation showed that RBC folate levels were positively correlated with the FHIT $m$ RNA $(r=0.17, \mathrm{P}=0.007)$ and protein $(r=0.21, \mathrm{P}=0.004)$ expression levels. According to median concentration of folate $(275.42 \mathrm{ng} / \mathrm{ml})$ in NC group, subjects 
Table III. FHIT gene methylation status in different groups.

\begin{tabular}{|c|c|c|c|c|c|c|}
\hline Group & $\mathrm{N}$ & $\begin{array}{c}\text { FHIT methylation } \\
\mathrm{n}(\%)\end{array}$ & $\chi^{2}$ & P-value & OR $(95 \% \mathrm{CI})$ & $\mathrm{OR}^{\mathrm{a}}(95 \% \mathrm{CI})$ \\
\hline $\mathrm{NC}$ & 80 & $4(5.0)$ & & & 1.00 & 1.00 \\
\hline CIN1 & 55 & $9(16.4)$ & 4.35 & 0.04 & $3.72(1.08-12.76)$ & $3.32(0.91-12.17)$ \\
\hline CIN2/3 & 55 & $14(25.5)$ & 9.74 & 0.002 & $6.49(2.01-20.99)$ & $5.43(1.53-19.32)$ \\
\hline $\mathrm{SCC}$ & 64 & $26(40.6)$ & 20.03 & $<0.001$ & $13.00(4.23-39.94)$ & $11.57(3.23-41.43)$ \\
\hline
\end{tabular}

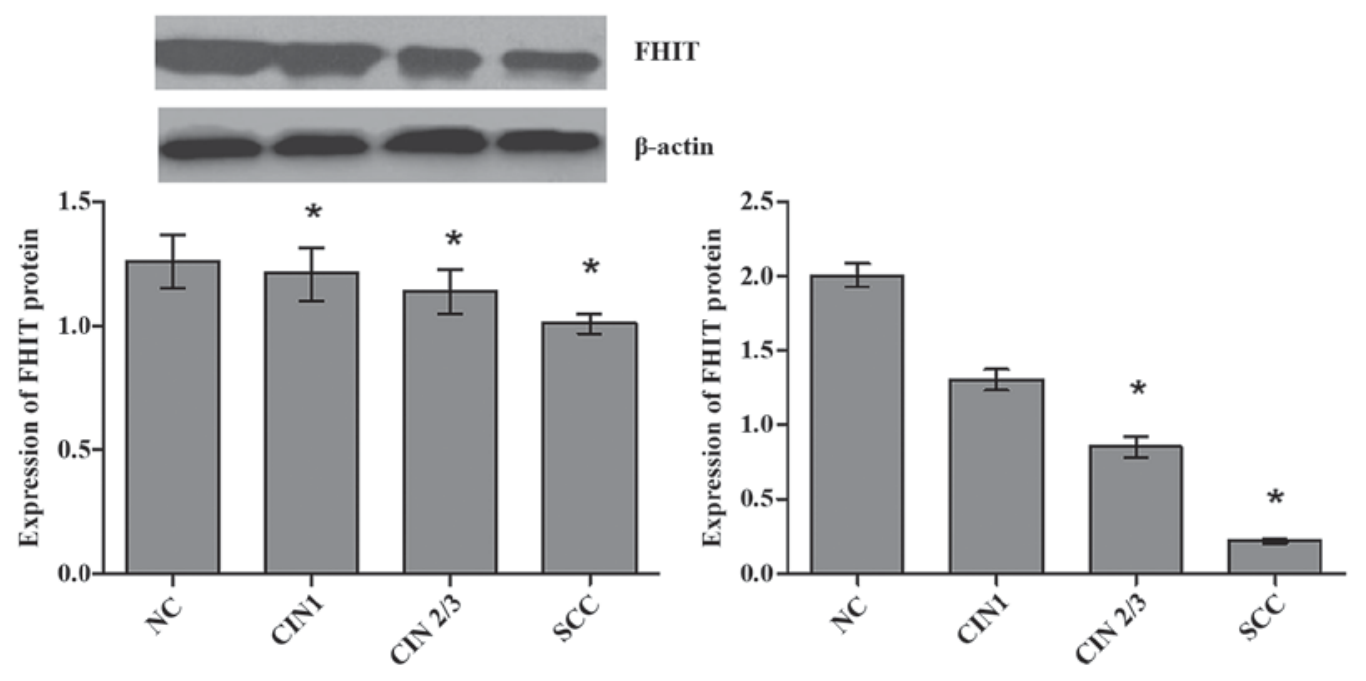

Figure 1. Protein and mRNA expression of FHIT in different cervical tissues ("Compared with the NC group, P<0.05). FHIT, Fragile histidine triad; NC, normal cervix; CIN, cervical intraepithelial neoplasm; SCC, squamous cell carcinoma.

were divided into low folate concentration group and high folate concentration group. The median expression levels of mRNA (2.00) and protein (1.26) in NC group as the cut-off point of FHIT mRNA and protein low level. FHIT gene methylation status, mRNA and protein expression levels were analyzed by RBC folate levels and the severity of cervical abnormality (Table IV). FHIT gene methylation rate and positive rate of low mRNA and protein expression was consistently higher in low folate concentration group than in high folate concentration group for all lesions groups. Table IV also showed that patients with lower folate status were more likely to become the status of FHIT gene methylation (CIN1: aOR=5.6, 90\% CI, 1.0-31.7; CIN2/3: $\mathrm{aOR}=47.5,90 \% \mathrm{CI}, 7.6-297.5$; SCC: $\mathrm{aOR}=52.3$, 90\% CI, 10.2-268.3), mRNA low expression (CIN1: aOR=2.6, 90\% CI, 0.9-7.1; CIN2/3: aOR=17.5, 90\% CI, 3.6-84.6; SCC: $\mathrm{aOR}=24.8,90 \% \mathrm{CI}, 2.8-47.6)$ and protein low expression (CIN1: $\mathrm{aOR}=5.6,90 \% \mathrm{CI}, 1.8-17.7 ; \mathrm{CIN} 2 / 3: \mathrm{aOR}=24.8$, 90\% CI, 7.6-76.8; SCC: aOR=44.7, 90\% CI, 7.2-280.1).

Effect of folate on cells proliferation and apoptosis. C33A and CaSki cells were treated with increasing concentrations of folate $(1-1,000 \mu \mathrm{g} / \mathrm{ml})$ for $48 \mathrm{~h}$. We found that the number of live cells was decreased in two cell lines with increased concentration of folate. The proliferation inhibition rate $(\mathrm{C} 33 \mathrm{~A}$ : $\mathrm{r}=0.98, \mathrm{P}<0.001$; CaSki: $\mathrm{r}=0.98, \mathrm{P}<0.001)$ and apoptosis rate (C33A: r=0.97, P<0.001; CaSki: $r=0.99, \mathrm{P}<0.001$ ) both gradually increased (Fig. 2) along with the rising concentrations of folate. Cell proliferation ability was inhibited by folate in dose-dependent manners, showing the higher the folate dosage, the higher the degree of inhibition. The inhibition rate and apoptosis rate of C33A cell was higher than CaSki cell, but there was no statistically significant difference $(\mathrm{P}>0.05)$.

FHIT gene methylation status and expression levels in C33A and CaSki cells treated with different concentrations of folate. Along with rising concentrations of folate, the degree of FHIT gene methylation in CC cells gradually weaken (Fig. 3). Both $\mathrm{C} 33 \mathrm{~A}$ and CaSki cell lines showed methylation positive at the concentration of 1 and $10 \mu \mathrm{g} / \mathrm{ml}$, partly methylation positive at the concentration of 100 and $250 \mu \mathrm{g} / \mathrm{ml}$, methylation negative at the concentration of 500 and $1,000 \mu \mathrm{g} / \mathrm{ml}$.

Expression levels of FHIT mRNA and protein in $\mathrm{C} 33 \mathrm{~A}$ (HPV-negative) and CaSki (HPV16-positive) cells were significantly different at different folate concentrations (Table V). Both expression levels of FHIT protein (Fig. 4) and mRNA increased in $\mathrm{C} 33 \mathrm{~A}$ and $\mathrm{CaSki}$ cell lines along with the rising 
Table IV. Methylation status and expression levels of FHIT by folate and cervical lesions status.

\begin{tabular}{|c|c|c|c|c|c|}
\hline & Variables & $\mathrm{NC} n(\%)$ & CIN1 n (\%) & CIN2/3 n (\%) & $\mathrm{SCC}$ n $(\%)$ \\
\hline \multicolumn{6}{|c|}{ FHIT methylation } \\
\hline$\geq 275.42$ & - & $38(47.5)$ & $17(30.9)$ & $4(7.3)$ & $8(12.5)$ \\
\hline$\geq 275.42$ & + & $2(2.5)$ & $4(7.3)$ & $4(7.3)$ & $4(6.3)$ \\
\hline \multicolumn{2}{|r|}{ aOR $(90 \% \mathrm{CI})$} & 1.0 & $1.7(0.8-3.6)$ & $9.2(3.0-28.5)$ & $3.7(1.5-9.2)$ \\
\hline$<275.42$ & - & $38(47.5)$ & $29(52.7)$ & $20(36.4)$ & $23(35.9)$ \\
\hline \multicolumn{2}{|r|}{ aOR $(90 \% \mathrm{CI})$} & 1.00 & $4.5(0.7-26.8)$ & $19.0(2.6-138.4)$ & $9.5(1.5-61.1)$ \\
\hline$<275.42$ & + & $2(2.5)$ & $5(9.1)$ & $27(49.1)$ & $32(50.0)$ \\
\hline \multicolumn{2}{|r|}{ OR $(90 \% \mathrm{CI})$} & 1.0 & $5.6(1.0-31.7)$ & $47.5(7.6-297.5)$ & $52.3(10.2-268.3)$ \\
\hline RBC-F & FHIT mRNA & & & & \\
\hline$\geq 275.42$ & $\geq 2.00$ & $17(21.3)$ & $9(16.4)$ & $2(3.6)$ & $0(0.0)$ \\
\hline$\geq 275.42$ & $<2.00$ & $23(28.7)$ & $12(21.8)$ & $6(10.9)$ & $12(18.8)$ \\
\hline \multicolumn{2}{|r|}{ aOR $(90 \% \mathrm{CI})$} & 1.0 & $0.9(0.3-2.7)$ & $4.4(0.9-22.5)$ & $3.5(1.6-28.6)$ \\
\hline$<275.42$ & $\geq 2.00$ & $23(28.7)$ & $11(20.0)$ & $12(21.8)$ & $1(1.6)$ \\
\hline \multicolumn{2}{|r|}{ aOR $(90 \% \mathrm{CI})$} & 1.0 & $1.0(0.3-2.9)$ & $2.2(0.4-12.4)$ & $4.3(1.8-10.5)$ \\
\hline$<275.42$ & $<2.00$ & $17(21.3)$ & $23(41.8)$ & $35(63.6)$ & $51(79.7)$ \\
\hline \multicolumn{2}{|r|}{ aOR (90\% CI) } & 1.0 & $2.6(0.9-7.1)$ & $17.5(3.6-84.6)$ & $24.8(2.8-47.6)$ \\
\hline RBC-F & FHIT protein & & & & \\
\hline$\geq 275.42$ & $\geq 1.26$ & $21(26.3)$ & $5(9.1)$ & $0(0.0)$ & $0(0.0)$ \\
\hline$\geq 275.42$ & $<1.26$ & $19(23.7)$ & $16(29.1)$ & $8(14.5)$ & $12(18.8)$ \\
\hline \multicolumn{2}{|r|}{ aOR $(90 \% \mathrm{CI})$} & 1.0 & $1.9(06-6.5)$ & $3.4(1.1-11.3)$ & $14.6(3.1-68.6)$ \\
\hline$<275.42$ & $\geq 1.26$ & $22(27.5)$ & $10(18.2)$ & $5(9.1)$ & $2(3.1)$ \\
\hline \multicolumn{2}{|r|}{ aOR $(90 \%$ CI) } & 1.0 & $3.5(1.1-11.5)$ & $7.9(2.9-21.2)$ & $10.2(4.1-25.1)$ \\
\hline$<275.42$ & $<1.26$ & $18(22.5)$ & $24(43.6)$ & $42(76.4)$ & $50(78.1)$ \\
\hline \multicolumn{2}{|r|}{ aOR $(90 \%$ CI) } & 1.0 & $5.6(1.8-17.7)$ & $24.8(7.6-76.8)$ & $44.7(7.2-280.1)$ \\
\hline
\end{tabular}

aOR, adjusted OR, multivariable adjustment described as table II. NC, normal cervix; CIN, cervical intraepithelial neoplasm; SCC, squamous cell carcinoma; CI, confidence interval; OR, odds ratio; FHIT, fragile histidine triad.
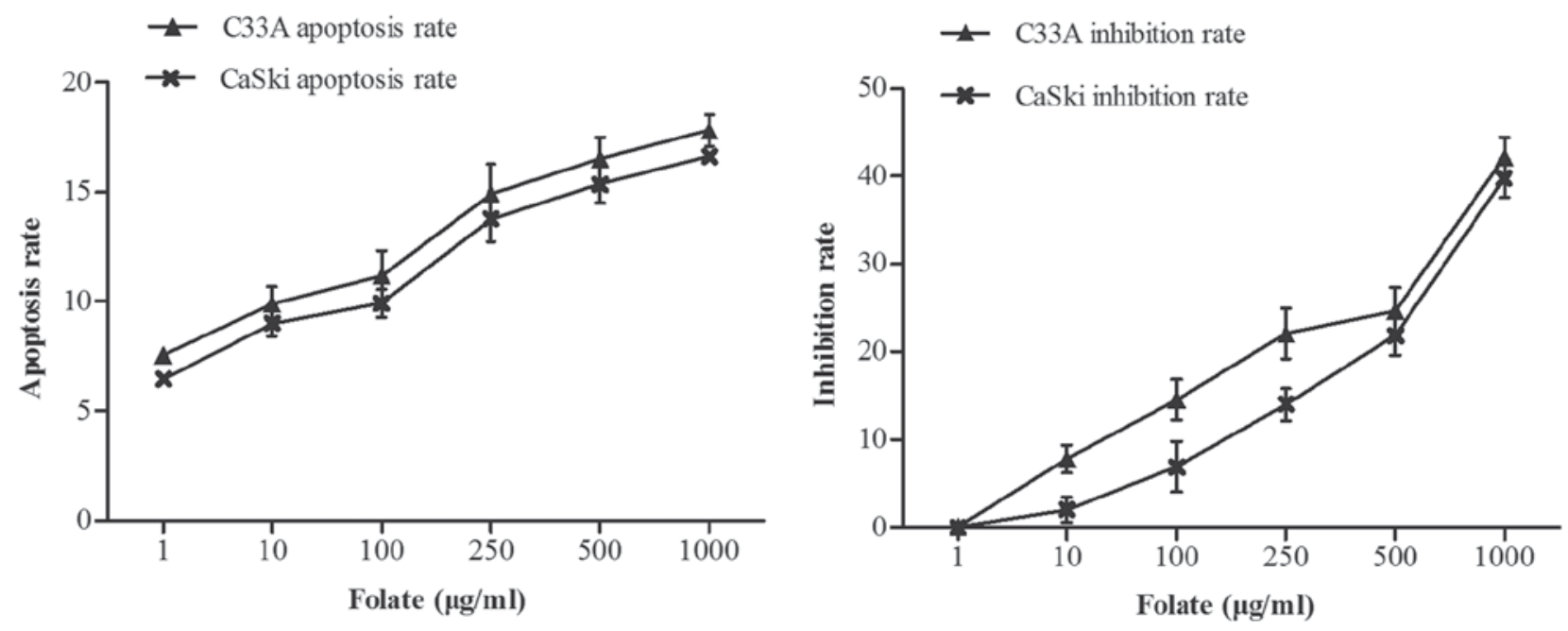

Figure 2. Effect of different folate concentration on cell proliferation and apoptosis.

concentrations of folate, showing positive correlation between folate and protein expression (C33A: $\mathrm{r}=0.969, \mathrm{P}<0.001$; CaSki: $\mathrm{r}=0.979, \mathrm{P}<0.001)$ and positive correlation between folate and mRNA expression (C33A: $\mathrm{r}=0.917, \mathrm{P}<0.001$; CaSki: $\mathrm{r}=0.930$, $\mathrm{P}<0.001$ ) (Fig. 5). Further multiple comparisons showed that except at concentration of $10 \mu \mathrm{g} / \mathrm{ml}$, FHIT mRNA and protein expression were all significantly different between $1.0 \mu \mathrm{g} / \mathrm{ml}$ (control) and other groups. At the same folate levels, both the expression of FHIT mRNA and protein were not different in $\mathrm{C} 33 \mathrm{~A}$ cell and in CaSki cell $(\mathrm{P}>0.05)$. 
Table V. Effects of folate on the expression of FHIT gene in two cervical cancer cells.

\begin{tabular}{|c|c|c|c|c|}
\hline \multirow[b]{2}{*}{ Folate $(\mu \mathrm{g} / \mathrm{ml})$} & \multicolumn{2}{|c|}{$\mathrm{C} 33 \mathrm{~A}$} & \multicolumn{2}{|c|}{ CasKi } \\
\hline & FHIT protein & FHIT mRNA & FHIT protein & FHIT mRNA \\
\hline 1 & $1.44 \pm 0.24$ & $4.58 \pm 1.87$ & $1.38 \pm 0.26$ & $3.39 \pm 1.37$ \\
\hline 10 & $1.47 \pm 0.31$ & $11.58 \pm 1.70$ & $1.43 \pm 0.21^{\mathrm{a}}$ & $8.68 \pm 2.45$ \\
\hline 100 & $1.62 \pm 0.26^{\mathrm{a}}$ & $29.56 \pm 1.94$ & $1.59 \pm 0.18^{\mathrm{a}}$ & $24.57 \pm 3.70$ \\
\hline 250 & $1.78 \pm 0.23^{\mathrm{a}}$ & $49.17 \pm 5.12$ & $1.73 \pm 0.21^{\mathrm{a}}$ & $35.09 \pm 6.62$ \\
\hline 500 & $1.79 \pm 0.14^{\mathrm{a}}$ & $52.94 \pm 8.24$ & $1.85 \pm 0.26^{\mathrm{a}}$ & $48.17 \pm 10.09^{a}$ \\
\hline 1,000 & $1.92 \pm 0.18^{\mathrm{a}}$ & $97.59 \pm 13.18^{\mathrm{a}}$ & $1.91 \pm 0.15^{\mathrm{a}}$ & $73.14 \pm 5.12^{\mathrm{a}}$ \\
\hline $\mathrm{F}$ & 68.77 & 24.74 & 103.05 & 20.97 \\
\hline $\mathrm{P}$ & $<0.001$ & $<0.001$ & $<0.001$ & $<0.001$ \\
\hline
\end{tabular}

${ }^{\mathrm{a} C}$ Compared with the control group, $\mathrm{P}<0.05$. FHIT, fragile histidine triad.

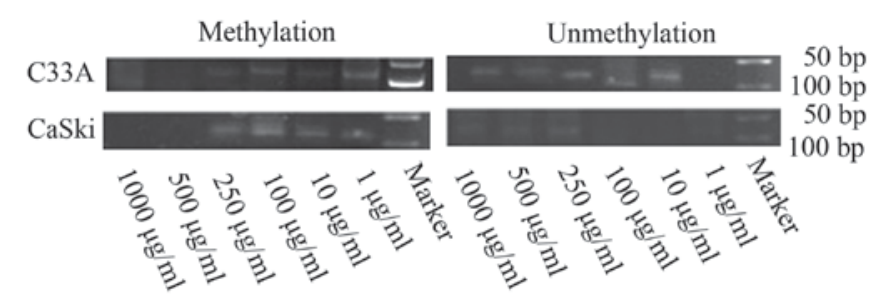

Figure 3. Effect of different folate concentration on FHIT gene methylation status of C33A and CaSki cells. FHIT, fragile histidine triad.

\section{Discussion}

$\mathrm{CC}$ is a complex disease caused by multiple factors, persistent HPV infection is reported to be a key factor determining risk of developing intraepithelial cervical lesions and CC. HPV, particularly types 16 , is transmitted sexually and when in contact with the transformation zone of the cervix is known to contribute to invasive cervical carcinoma. But recurrent or persistent infection with the oncogenic HPV is necessary but not sufficient for the development of CC $(25,26)$, there may be other carcinogenic factors or some factors that work together with HPV for carcinogenesis. Our study was designed to comprehensively evaluate the effects of folate on the progression from the NC, low-grade cervical intraepithelial neoplasia, high-grade cervical intraepithelial neoplasia to $\mathrm{CC}$ at the angle of groups, meanwhile, the effect of folate on cervical carcinogenesis was demonstrated by folate intervention at the angle of vitro.

There have not been largely conducted epidemiologic studies designed to examine where in the cervical carcinogenesis continuum nutrients such as folate and vitamin B 12 may influence the natural history of the disease (27). Folate participates in the synthesis of DNA as the precursor of purine and pyrimidine and is directly involved in DNA methylation process, through provision of methyl groups by the 5-methyltetrahydrofolate, these biological functions suggest changes of folate levels have the biological basis of cancer risk. Our results based on the population and in vitro studies showed that levels of RBC folate were decreased with the severity of cervical lesions, proliferation inhibition rate and apoptosis rate gradually increased in CC cells (HPV16 positive or negative) with the increasing folate concentrations. Shyr and colleagues (28) reported folic acid (0-10 $\mu \mathrm{mol} / \mathrm{l})$ concentration-dependently decreased DNA synthesis and proliferation in cultured human umbilical venous endothelial cells (HUVEC). Other research have shown that folic acid can promote dose dependent cell proliferation in folate receptor $\alpha$ (FR $\alpha$ )-positive HeLa cells, but not in FR $\alpha$-negative HEK293 cells (29). The study of Huang indicated that hepatoma HepG2 cells cultivated in folate-deficient medium have a low folate concentration, decreased growth and viability, and increased apoptotic propensity (30). Hearnden (31) recently demonstrated that head and neck SCC (HNSCC) cells cultured in methyl donor deplete conditions showed significantly reduced cell proliferation, impaired cell migration, and a dose-dependent increase in apoptosis when compared to cells cultured in complete medium. Maybe the mechanism of the effects of folate on proliferation and apoptosis of CC cells is complex and needs to be further studied.

FHIT belongs to histidine triad gene family, which encodes Hydrolase of Ap3A and is located on chromosome 3p14.2 and encompasses the common fragile site FRA3B. FHIT is now considered as a tumor suppressor gene and the loss or aberrant transcripts of FHIT gene is associated with carcinogenesis. FHIT inhibits the serine/threonine kinase Akt, a key effector in PI3K pathway, promoting survival and cell growth in response to extracellular signals. The tumor suppressor genes function of this gene is reflected by regulation of programmed cell death and suppression of tumor metastasis. FHIT protein also plays a role in the modulation of response to DNA damage, for example, preventing the replication of stress-induced DNA damage $(21,32)$. DNA methylation is a common well-balanced regulatory process and important epigenetic determinant in gene expression (an inverse relationship). Promoter hypermethylation of tumor suppressor genes leads to silencing or diminishing expression of tumor suppressor gene in carcinoma and is recognized as the hallmark of human cancer (33-35). Multiple studies have found the reduction of FHIT expression in precancerous lesions, indicating its potential suppressing role in carcinogenesis (36). Our results showed that mtehylation 

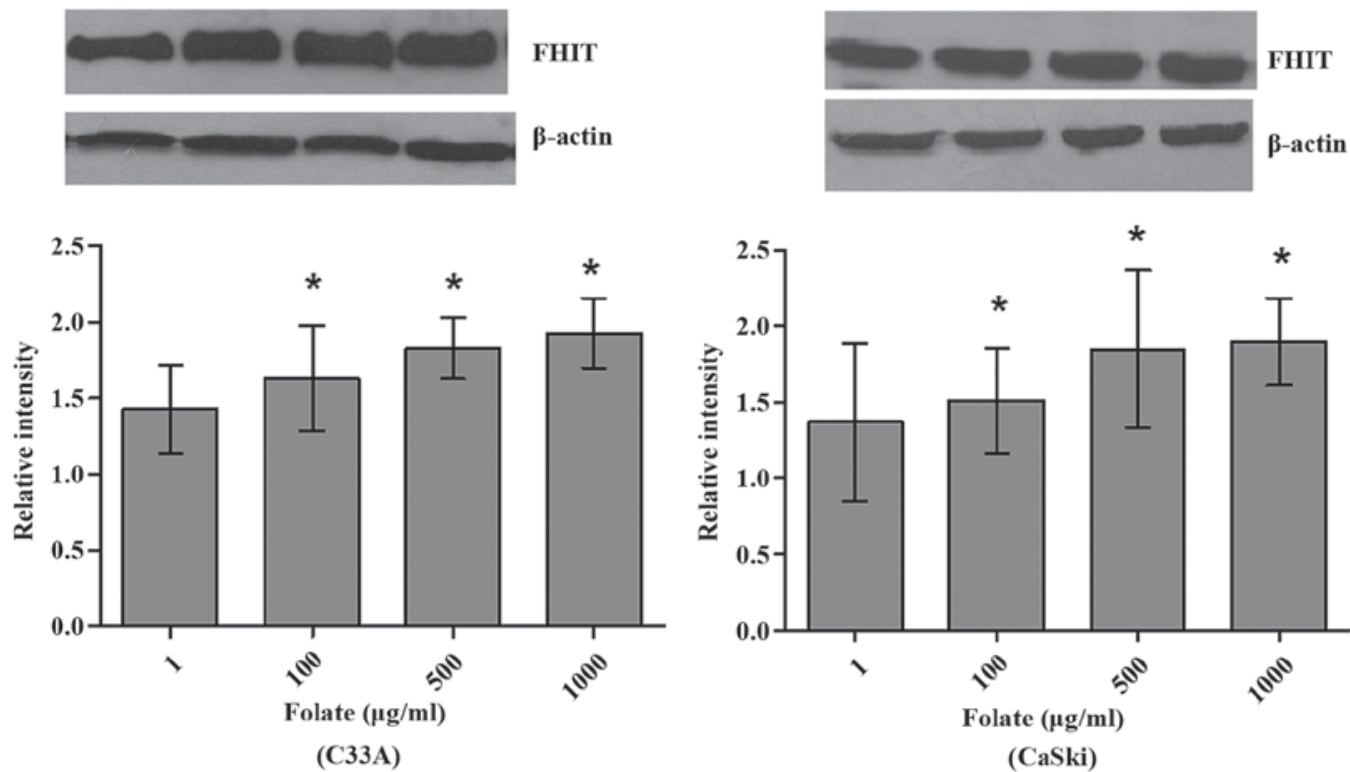

Figure 4. C33A and CaSki cells exposed to folate. Protein expression of FHIT gene in different cervical cancer cells ("P $<0.05$ vs. the control group). FHIT, fragile histidine triad.
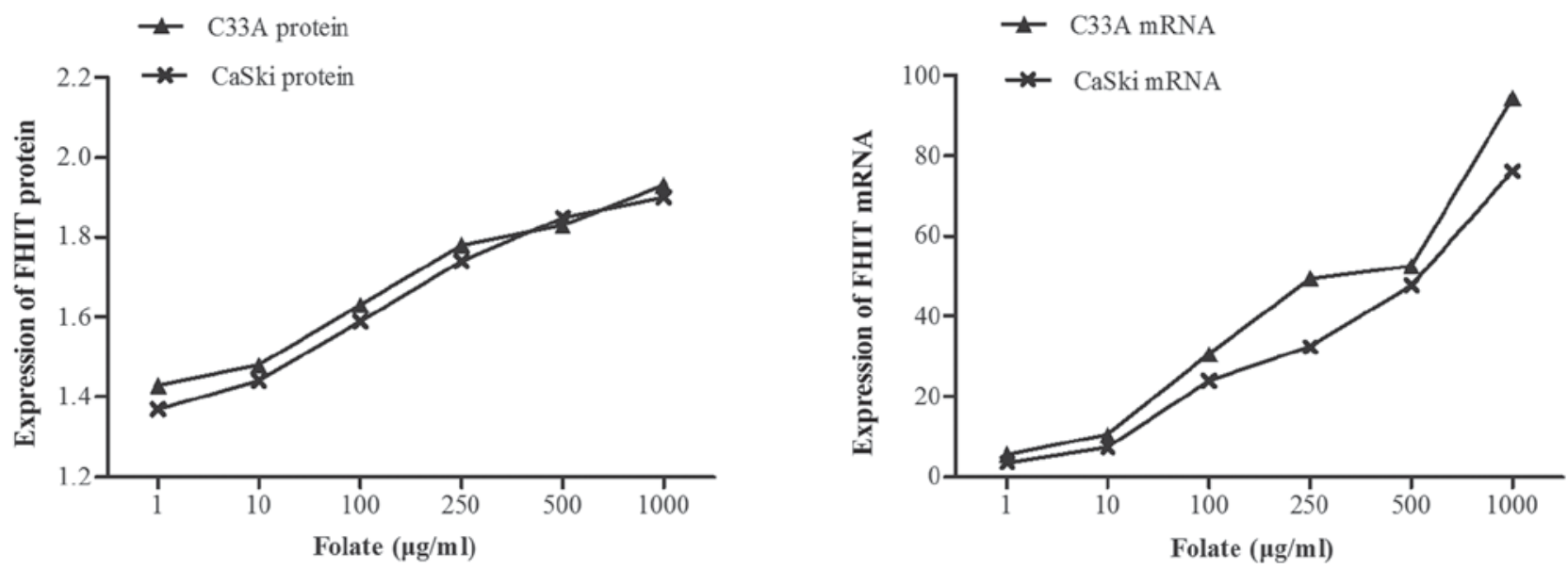

Figure 5. Expression of FHIT mRNA and protein in C33A and CaSki cell lines treated with different concentrations of folate (1-1,000 $\mu \mathrm{g} / \mathrm{ml})$. FHIT, fragile histidine triad.

rate of FHIT gene increased, however, expression of FHIT protein and mRNA steadily decreased with the severity of cervical lesions, which suggested that FHIT gene function loss significantly contributed to $\mathrm{CC}$ as well as its precancerous neoplastic lesions. Czarnecka et al (21). demonstrated that FHIT promoter hypermethylation status, low protein in patients with non-small cell lung cancer, but high mRNA levels. Widschwendter et al (37) also reported an increase in the frequency of promoter methylation in tumor suppressor genes DAPK and CDH1 from low-grade cervical neoplasia to $\mathrm{CC}$ in their small study of Austrian women.

In mammals, the vitamin folate is a key source of the one carbon group used to methylate DNA, DNA methylation is an epigenetic modification critical to normal genome regulation and development (11). So the biological function of folate and FHIT suggest that influence of folate to cervical carcinogenesis may be associated with the activity and function of FHIT gene, poor folate status may contribute to CC risk through effects on one-carbon metabolism and DNA methylation (38) there is enormous interest in assessing the potential for changes in folate intake to modulate DNA methylation as a mechanistic link to cancer. Research in rat liver showed a significant $20 \%$ decrease in genomic DNA methylation associated with a severe degree of dietary folate deficiency of 4 weeks' duration (39). Currently, correlation between folate and FHIT gene epigenetic characteristics in the progression of cervical carcinogenesis still remains unclear, the effect of folate on FHIT gene methylation and expression is largely unknown. In our study, our results revealed that FHIT gene methylation rate and positive rate of low mRNA and protein expression was consistently higher in low folate concentration group than in high folate concentration group. In vitro studies found that the degree of FHIT gene methylation in HPV16 positive and negative CC cells gradually weaken with the increased supplementation of folate, however, expression levels of FHIT protein and mRNA were strengthened. The study of Liu et al (40) have investigated the effects of maternal folic 
acid (FA) supplementation on genes expressions relating to cell apoptosis (p53, Bcl-2 and Bax) in intrauterine growth retarded (IUGR) and normal body weight (NBW) piglets, and showed that the expression of p53 and Bax was higher, but expression of Bcl-2 was significantly lower in jejunum of IUGR piglets compared with NBW piglets.

The results of this cross-sectional study support a role for folate in modulating the risk of CC. There was complicated relationship between folate and FHIT gene hypermethylation. Folate is likely to be only one of many factors influencing promoter hypermethylation of tumor suppressor genes. In-depth studies, such as prospective cohort study, will provide the etiological evidence of folate and tumor suppressor genes in $\mathrm{CC}$.

\section{Acknowledgments}

This study was supported by the National Natural Science Foundation of China (nos. 81273157, 30872166 and 81473060) and Special Public Welfare Industry Research of National Health and Family Planning Commission (no. 20140 2010).

\section{References}

1. Forouzanfar MH, Foreman KJ, Delossantos AM, Lozano R Lopez AD, Murray CJ and Naghavi M: Breast and cervical cancer in 187 countries between 1980 and 2010: A systematic analysis. Lancet 378: 1461-1484. 2011.

2. Depuydt CE, Thys S, Beert J, Jonckheere J, Salembier G and Boqers JJ: Linear viral load increase of a single HPV-type in women with multiple HPV infections predicts progression to cervical cancer. Int J Cancer 139: 2021-2032, 2016.

3. Wang JT, Ding L, Jiang SW, Hao J, Zhao WM, Zhou Q, Yang ZK and Zhang L: Folate deficiency and aberrant expression of DNA methyltransferase 1 were associated with cervical cancerization. Curr Pharm Des 20: 1639-1646.

4. Blount BC, Mack MM, Wehr CM, MacGregor JT, Hiatt RA, Wang G, Wickramasinghe SN, Everson RB and Ames BN: Folate deficiency causes uracil misincorporation into human DNA and chromosome breakage: Implications for cancer and neuronal damage. Proc Natl Acad Sci U S A 94: 3290-3295, 1997.

5. Duthie SJ: Folic acid deficiency and cancer: Mechanisms of DNA instability. Br Med Bull 55: 578-592, 1999.

6. Flatley JE, Sarqent A, Kitchener HC, Russell JM and Powers HJ: Tumour suppressor gene methylation and cervical cell folate concentration are determinants of high-risk human papillomavirus persistence: A nested case control study. BMC Cancer 14 803, 2014.

7. Kobayashi LC, Limburg H, Miao Q, Woolcott C, Bedard LL, Massey TE and Aronson KJ: Folate intake, alcohol consumption and the methyl enetetrahydrofolate reductase (MTHFR) C677T gene polymorphism: influence on prostate cancer risk and interactions. Front Oncol 2: 100, 2012.

8. Choi SW and Mason JB: Folate status: Effects on pathways of colorectal carcinogenesis. J Nutr 132 (suppl 8): 2413S-2418S, 2002

9. Kim YI: Folate and carcinogenesis: Evidence, mechanisms and implications. J Nutr Biochem 10: 66-88, 1999.

10. Flatley JE, McNeir K, Balasubramani L, Tidy J, Stuart EL, Young TA and Powers HJ: Folate status and aberrant DNA methylation are associated with HPV infection and cervical pathogenesis. Cancer Epidemiol Biomarkers Prev 18: 2782-2789, 2009.

11. Sun XS, Ding L, Chen F, Wu T and Wang J: Effects of folate deficiency with HPVl6 infection on cervix cancerization. Zhonghua Liu Xing Bing Xue Za Zhi 35: 437-41, 2014.

12. Kanai Y and Hirohashi S: Alterations of DNA methylation associated with abnormalities of DNA methyltransferases in human cancers during transition from a precancerous to a malignant state. Carcinogenesis 28: 2434-42, 2007.

13. Jones PA: DNA methylation errors and cancer. Cancer Res 56: 2463-2467, 1996.
14. Zhang A, Månér S, Betz R, Angström T, Stendahl U, Bergman F, Zetterberg $A$ and Wallin KL: Genetic alterations in cervical carcinomas: Frequent low-level amplifications of oncogenes are associated with human papillomavirus infection. Int $\mathrm{J}$ Cancer 101: 427-433, 2002.

15. Kulis M and Esteller M: DNA methylation and cancer. Adv Genet 70: 27-56, 2010

16. Abouzeid HE, Kassem AM, Abdel Wahab AH, El-mezayen HA, Sharad HA and Abdel Rahman S: Promoter hypermethylation of RASSF1A, MGMT and HIC-1 genes in benign and malignant colorectal tumors. Tumour Biol 32: 845-852, 2011.

17. Su Y, Wang X, Li J, Xu J and Xu L: The clinicopathological significance and drug target potential of FHIT in breast cancer, a meta-analysis and literature review. Drug Des Devel Ther 9: 5439-5445, 2015.

18. Al-Temaimi RA, Jacob S, Al-Ali W, Thomas DA and Al-Mulla F: Reduced FHIT expression is associated with mismatch repair deficient and high $\mathrm{CpG}$ island methylator phenotype colorectal cancer. J Histochem Cytochem 61: 627-638, 2013.

19. Herzog CR, Crist KA, Sabourin CL, Kelloff GJ, Boone CW, Stoner GD and You M: Chromosome 3p tumor suppressor gene alterations in cervical carcinomas. Mol Careinog 30: 159-168, 2001.

20. Liu XZ, Nan J, Li J, Li Y, Ding L and Wang JT: Interaction between fragile histidine triad methylation, protein expression and human papillomavirus 16 infection in cervical carcinogenesis. Zhonghua Liu Xing Bing Xue Za Zhi 37: 858-862, 2016 (In Chinese).

21. Czarnecka KH, Miqdalska-Sek M, Domanska D, Pastuszak-Lewandoska D, Dutkowska A, Kordiak J, Nawrot E, Kiszlkiewicz J, Antczak A and Brzeziańska-Lasota E: FHIT promoter methylation status, low protein and high mRNA levels in patients with non-small cell lung cancer. Int J Oncol 49: $1175-1184,2016$

22. Wang JT, Gao ES, Cheng YY, Yan JW and Ding L: Analysis on synergistic action between estrogen, progesterone and human papillomaviruses in cervical cancer. Zhonghua Liu Xing Bing Xue Za Zhi 26: 370-373, 2005 (In Chinese).

23. Bai LX, Wang JT, Ding L, Jiang SW, Kang HJ, Gao CF, Chen X, Chen $C$ and Zhou Q: Folate deficiency and FHIT hypermethlation and HPV 16 infection promote cervical cancerization. Asian Pac J Cancer Prev 15: 9313-9317, 2014.

24. Chen X, Wang J, Bai L, Ding L, Bai L, Xu J and Sun XS: Interaction between folate deficiency and aberrant expression related to fragile histidine triad gene in the Progression of cervical cancerization. Zhonghua Liu Xing Bing Xue Za Zhi 36: 387-392, 2015 (In Chinese).

25. Guzmán-Olea E, Bermúdez-Morales VH, Peralta-Zaragoza O and Torres-Poveda K, Madrid-Marine V: Molecular mechanism and potential targets for blocking hpv-induced lesion development. J Oncol 2012: 278312, 2012.

26. Kyrqiou M, Mitra A and Moscicki AB: Does the vaginal microbiota plays a role in the development of cervical cancer? Trans Res 179: 168-182, 2017.

27. Piyathilake CJ, Henao OL, Macaluso M, Cornwell PE, Melleth S, Heimburqer and Partridqe EE: Folate is associated with the natural history of high-riskt human papillomaviruses: Cancer Res 64: 8788-8793, 2004

28. Lin SY,Lee WR, Su YF, Hsu SP, Lin HC,Ho PY,Hou TC, Chou YP, Kuo CT and Lee WS: Folic acid inhibits endothelial cell proliferation through activating the cSrc/ERK $2 / \mathrm{NF}-\mathrm{jB} / \mathrm{p} 53$ pathway mediated by folic acid receptor. Angiogenesis 15: 671-683, 2012.

29. Hansen MF, Greibe E, Skovbjerq S, Rohde S, Kristensen AC, Jensen TR, Stentoft C, Kjær KH, Kronborq CS and Martensen PM: Folic acid mediates activation of the pro-oncogene STAT3 via the Folate Receptor alpha. Cell Signal 27: 1356-1368, 2015.

30. Huang RF, Ho YH, Lin HL, Wei JS and Liu TZ: Folate deficiency induces a cell cycle-specific apoptosis in HepG2 cells. J Nutr 129: 25-31, 1999.

31. Hearnden V, Powers HJ, Elmoqassabi A, Lowe R and Murdoch C: Methyl-donor depletion of head and neck cancer cells in vitro establishes a less aggressivetumour cell phenotype. Eur J Nutr: March 1, 2017 (Epub ahead of print).

32. Sozzi G, Pastorino U, Moiraghi L, Tagliabue E, Pezzella F, Ghirelli C, Tornielli S, Sard L, Huebner K, Pierotti MA, et al: Loss of FHIT function in lung cancer and preinvasive bronchial lesions. Cancer Res 58: 5032-5037, 1998.

33. Kwan KY and Wong CS. DNA methylation of tumor suppressor protein-coding and non-coding genes in multiple myeloma. Epigenomics 7: 985-1001, 2015. 
34. 1liopoulos D, Guler G, Han SY, Johnston D, Druck T, McCorkell KA, Palazzo J, McCue PA, Baffa R and Huebner K: Fragile genes as biomarker: Epigenetic control of WWOX and FHIT in lung, breast and bladder cancer. Oncogene 24: 1625-1633, 2005.

35. Dhillon VS, Shahid M and Husain SA: CpG methylation of the FHIT, FANCF, cyclin-D2, BRCA2 and RUNX3 genes in Granulosa cell tumors (GCFs) of ovarian origin. Mol Cancer 3: 33, 2004

36. Geng X, Pu W, Tan Y, Lu Z, Wang A, Tan L, Chen S, Guo S, Wang $\mathrm{J}$ and Chen $\mathrm{X}$ : Quantitative assessment of the diagnostic role of FHIT promoter methylation in non-small cell lung cancer. Oncotarget 8: 6845-6856, 2017.

37. Widschwendter A, Gattringer C, Ivarsson L, Fiegl H, Schneitter A, Ramoni A, Müller HM, Wiedemair A, Jerabek S, Müller-Holzner E, et al: Analysis of aberrant DNA methylation and human papillomavirus DNA in cervicovaginal specimens to detect invasive cervical cancer and its precursors. Clin Cancer Res 10: 3396-3400, 2004
38. Zhao Y, Guo C, Hu H, Zheng L, Ma J, Jiang L, Zhao E and $\mathrm{Li} \mathrm{H}$ : Folate intake, serum folate levels and esophageal cancer risk: An overall and dose-response meta-analysis. Oncotarget 8: 10458-10469, 2017.

39. Kim YI: Folate and DNA methylation: A mechanisticlink between folate deficiency and colorectal cancer? Cancer Epidemiol Biomarkers Prev 13: 511-519, 2004.

40. Liu J, Chen D, Mao X and Yu B: Effects of maternal folic acid supplementation on morphology and apoptosis-related gene expression in jejunum of newborn intrauterine growth retarded piglets. Arch Anim Nutr 65: 376-385, 2011. 